\title{
Valganciclovir in the treatment of cytomegalovirus retinitis in HIV-infected patients
}

This article was published in the following Dove Press journal:

Clinical Ophthalmology

27 February 2010

Number of times this article has been viewed

\author{
A Jayaprakash Patil 1,2,3 \\ Ashish Sharma ${ }^{1,4}$ \\ M Cristina Kenney' \\ Baruch D Kuppermann' \\ 'Department of Ophthalmology, \\ Gavin S Herbert Eye Institute, \\ University of California, Irvine, \\ Irvine, CA, USA; '2Department \\ of Ophthalmology, Summa \\ Health System, Akron, OH, USA; \\ ${ }^{3}$ Northeastern Ohio Universities \\ Colleges of Medicine and Pharmacy, \\ Rootstown, OH, USA; ${ }^{4}$ Department \\ of Ophthalmology, Bascom Palmer \\ Eye Institute, Miami, FL, USA
}

\begin{abstract}
Oral valganciclovir is a new and highly efficacious alternative to the chronic administration of ganciclovir in the treatment of cytomegalovirus (CMV) retinitis in HIV-infected patients. In addition to its excellent bioavailability and favorable pharmacokinetic profile, valganciclovir has also proved cost effective and is the most widely used drug in the armamentarium for the treatment of CMV retinitis. Valganciclovir is a prodrug of ganciclovir, the erstwhile commonly used therapy. In March 2001, the US Food and Drug Administration approved valganciclovir for the induction and maintenance treatment of CMV disease, including CMV retinitis. Valganciclvoir has compared favorably with both oral and intravenous treatments for induction and maintenance therapy with ganciclovir. The reduced pill burden and the ease of oral administration has helped avoid the risks associated with intravenous therapy. The most serious adverse event is neutropenia, which makes the patient susceptible to infections. In the current review, we have compiled all the available evidence-based information on valganciclovir.
\end{abstract}

Keywords: CMV retinitis, ganciclovir, valganciclovir

\section{Introduction}

Cytomegalovirus (CMV) retinitis is the leading cause of visual impairment in patients with human immunodeficiency virus (HIV), and typically occurs in HIV-positive individuals with CD4 count below 50 cells $/ \mathrm{mm}^{3} \cdot{ }^{1-3}$ Historically, the most utilized antiviral agent has been ganciclovir, which was initially licensed as an intravenous agent. In an attempt to make an oral preparation with convenient dosing that has the safety profile, efficacy and bioavailability comparable to ganciclovir, the prodrug was developed. ${ }^{4,5}$ Valganciclovir, the valine ester of ganciclovir, was the first systemic agent found to be as effective as intravenous ganciclovir, and is the oral prodrug of the popular anti-CMV drug ganciclovir. Valganciclovir has answered the great need of patients with CMV retinitis for an injection free medication in the induction and maintenance phases of therapy. ${ }^{5,6} \mathrm{In}$ this review we highlight the pharmacokinetics and pharmacodynamics of valganciclovir and address the issues of clinical trials and related studies. We also discuss valganciclovir drug interactions, drug economics and efficacy as a substitute to intravenous ganciclovir.

With the advent of highly active anti-retroviral therapy (HAART), the prevalence of CMV retinitis has drastically decreased by $75 \%-90 \%$ from a pre-HAART era prevalence of $30 \%$ or more in people with advanced AIDS. ${ }^{7}$ Of the patients having access to HAART, the prevalence is now less than $5 \% .{ }^{8}$ Nevertheless, CMV retinitis still remains the chief vision threatening infection in HIV infected patients. ${ }^{9}$ Untreated retinitis typically progresses and can lead to the development of atrophic retinal holes and subsequent retinal detachment. Approximately $15 \%$ of patients develop retinal
Correspondence: Baruch D Kuppermann Department of Ophthalmology, Gavin S Herbert Eye Institute,

University of California Irvine,

I I 8 Med Surge I, Irvine,

CA 92697 , USA

Tel + I 9498246256

Fax +I 9498244015

Email bdkupper@uci.edu 
detachment even before the treatment is initiated. ${ }^{10,11}$ Thus CMV retinitis is thought to profoundly affect ocular morbidity, and quality of life, unless timely treatment is instituted. Valganciclovir hydrochloride (Valcyte ${ }^{\circledR}$; Hoffmann-La Roche Inc., Nutley, NJ, USA) is an US Food and Drug Administration (FDA)-approved antiviral medication for the treatment of CMV disease that has revolutionized the treatment of CMV retinitis. Studies WV 15376 and WV 15705 were the two pivotal studies that established the bioequivalence, efficacy, and safety of oral valganciclovir in comparison with oral and intravenous ganciclovir. These studies formed the basis for clinical use of oral valganciclovir and have played an important role in the drug development. In this review we have compiled all the information on valganciclovir available from PubMed and results from a Google search from December 1996 to June 2009. The information was also derived from clinical trials, case reports, abstracts and previous reviews. Additional references were obtained from the bibliographic data of published review articles. The valganciclovir package insert also provided useful information. The two pivotal studies are described in detail below.

\section{Pharmacokinetics}

Valganciclovir hydrochloride is a hydrochloride salt of the L-valyl ester of ganciclovir. It is a prodrug of ganciclovir. Upon absorption, it is extensively and rapidly hydrolyzed into the active forms of ganciclovir, which is a mixture of two diastereomers, by hepatic and gut esterases. Hence the pharmacokinetics of oral valganciclovir is essentially the same as that of intravenous ganciclovir. ${ }^{12}$ Treatment with valganciclovir/ ganciclovir typically stabilizes retinal lesions in two to four weeks, and frequently there is a complete response in one month. Ganciclovir (intravenous) treatment of CMV retinitis is associated with clearing of CMV viremia and CMV DNA from the buffy coat of the infected blood in 7-8 days. ${ }^{13}$

Protein binding of valganciclovir has not been established due to rapid and extensive conversion of oral valganciclovir to ganciclovir. Kidneys excrete valganciclovir as ganciclovir, both by glomerular filtration and active tubular secretion. Hence the plasma level of ganciclovir and thus terminal half-life is increased in patients with renal impairment. ${ }^{14}$ Pharmacokinetic parameters are described in Table 1.

\section{Bioavailability}

Oral valganciclovir at the standard dose of $900 \mathrm{mg}$ once a day produces a daily systemic exposure which is 1.7-fold greater than that attained with oral ganciclovir at the standard dose of $1000 \mathrm{mg}$ three times daily. In addition, the area under
Table I Pharmacokinetics of valganciclovir ${ }^{22}$

\begin{tabular}{llll}
\hline Feature & Valganciclovir & $\begin{array}{l}\text { Intravenous } \\
\text { ganciclovir }\end{array}$ & $\begin{array}{l}\text { Ganciclovir } \\
\text { capsules }\end{array}$ \\
\hline Dosage & $\begin{array}{l}900 \mathrm{mg} \text { qd } \\
\text { with food }\end{array}$ & $\begin{array}{l}5 \mathrm{mg} / \mathrm{kg} \\
\text { once daily }\end{array}$ & $\begin{array}{l}1000 \mathrm{mg} \text { tid } \\
\text { with food }\end{array}$ \\
$\begin{array}{l}\text { Plasma half-life } \\
\text { (hours) }\end{array}$ & 4.08 & 2.9 & $4.4^{20}$ \\
$\mathrm{AUC}_{24} \mu \mathrm{g} . \mathrm{h} / \mathrm{mL}$ & $29.1 \pm 9.7$ & $26.5 \pm 5.9$ & $12-19.2$ \\
$\begin{array}{l}\text { Oral } \\
\text { Bioavailability (\%) }\end{array}$ & $60^{4}$ & Not applicable & $6^{24}$ \\
\hline
\end{tabular}

Abbreviations: qd, once a day; tid, three times daily; AUC, area under curve.

curve at 24 hours/drug exposure (AUC24) of valganciclovir increased from $24 \%$ to $56 \%$ when compared from fed state to the fasting state. ${ }^{6}$ As a result, valganciclovir has greater CMV-suppressing ability than ganciclovir. ${ }^{15}$

The absolute bioavailability of oral valganciclovir is approximately $60 \%,{ }^{16}$ which is 10 times higher than ganciclovir bioavailability after oral administration. ${ }^{17}$ The peptide-mediated active transport of valganciclovir due to the presence of valine moiety explains its increased bioavailability. ${ }^{17-19}$ A dose of $900 \mathrm{mg} /$ day of valganciclovir produces a daily exposure equivalent to the $5 \mathrm{mg}$ /day daily intravenous dose of ganciclovir. ${ }^{6,17}$ Oral ganciclovir was developed as an initial attempt to provide a more convenient therapeutic regimen for ganciclovir (Cytovene ${ }^{\circledR}$; Roche Laboratories), but was found to have low and variable bioavailability (6\%-9\%) compared to oral valganciclovir (60\%). In clinical trials oral ganciclovir was found to be inferior to intravenous ganciclovir for the induction phase, as it reached a subtherapeutic serum level. ${ }^{20,21}$ It was however approved by the FDA for maintenance phase therapy of CMV retinitis.

\section{Mechanism of action}

Ganciclovir is the only metabolite of valganciclovir and it undergoes no further metabolism. Intracellular phosphorylation of ganciclovir forms ganciclovir triphosphate, which is the most active form. Ganciclovir triphosphate inhibits viral DNA synthesis by competing with deoxyguanosine. This prevents the incorporation of deoxyguanosine into elongating viral DNA, thus terminating DNA synthesis, chiefly of the group of herpes viruses. Ganciclovir monophosphate formed after the release of pyrophosphate is also incorporated into the growing viral DNA chain further slowing the process of replication. ${ }^{22}$

\section{Clinical trials}

Based on the equivalent pharmacokinetic profile and AUC24 of oral valganciclovir compared to the conventional intravenous ganciclovir, Hoffmann-La Roche applied for FDA 
approval in $1997 .{ }^{12}$ The initial FDA application was not approved based on the pharmacokinetics alone. Roche was asked to complete another randomized controlled trial demonstrating the equivalence between the two drugs for the induction therapy of CMV retinitis. ${ }^{5}$

\section{Study WV I5376}

Unlike a traditional head-to-head study, this pivotal trial, Study WV $15376,{ }^{5,22}$ was a noninferiority study designed to prove that oral valganciclovir was not $10 \%$ worse than intravenous ganciclovir. The study enrolled 160 patients with newly diagnosed CMV retinitis; 80 of them received induction therapy with intravenous ganciclovir $5 \mathrm{mg} / \mathrm{kg}$ for three weeks and the remaining 80 received induction therapy with oral valganciclovir $900 \mathrm{mg}$ twice daily for three weeks. The patients were followed with the same therapy once daily for one week. All patients were then placed on maintenance treatment with oral valganciclovir $900 \mathrm{mg}$ once daily. Retinal photographs were obtained at baseline visit and then week two and week four and evaluated by masked reviewers. Although most patients had zone-3 retinitis, 24\% in each arm had zone- 1 retinitis. The mean CD4 cell count at baseline was 54 cells $/ \mathrm{mm}^{3}$ in the intravenous ganciclovir arm, and 58 cells $/ \mathrm{mm}^{3}$ in the oral valganciclovir arm. The median HIV RNA at baseline was $4.9 \log 10$ copies/mL in the intravenous ganciclovir arm, and $4.8 \log 10$ copies $/ \mathrm{mL}$ in the oral valganciclovir arm. This registrational study is summarized in Table 2.

The primary efficacy end point of the study was the progression of retinitis during the first four weeks of the therapy. Analysis of the primary endpoint revealed that seven patients $(10 \%)$ in each treatment arm had progression of retinitis after four weeks as determined by the masked reviewer. The secondary efficacy end point was the time to CMV retinitis progression. This was not significantly different between the two groups (219 days in the ganciclovir arm and 226 days in the valganciclovir arm). Of importance, the mean time to progression of CMV retinitis in this trial conducted during the HAART era was substantially longer than the times observed in studies before the introduction of HAART (approximately 70 days). No significant difference in serious adverse events between the two drugs was noted in the study except for the increased catheter related infectious complications in intravenous ganciclovir group. ${ }^{23}$

\section{Study WV 15705}

Study WV $15705^{24}$ enrolled 212 patients who received maintenance treatment with oral valganciclovir for CMV retinitis. Patients who were receiving intravenous ganciclovir for maintenance treatment of CMV retinitis were eligible for enrollment. The results of the study established the safety profile of oral valganciclovir in AIDS patients with

Table 2 Summary of the valganciclovir registrational study WV $15376^{22}$

\begin{tabular}{|c|c|}
\hline $\begin{array}{l}\text { Total number of patients enrolled } \\
\text { and randomized to either arms }\end{array}$ & 160 \\
\hline $\begin{array}{l}\text { Number of patients } \\
\text { completing the study }\end{array}$ & 146 \\
\hline Induction therapy & $\begin{array}{l}\text { Oral valganciclovir arm: } 900 \mathrm{mg} \text { bid for three weeks followed by } 900 \mathrm{mg} \text { once daily for one week. } \\
\text { Intravenous ganciclovir arm: } 5 \mathrm{mg} / \mathrm{kg} \text { bid for three weeks followed by } 5 \mathrm{mg} / \mathrm{kg} \text { once daily for one week. }\end{array}$ \\
\hline Maintenance therapy & All patients were given the maintenance therapy of valganciclovir of $900 \mathrm{mg}$ once daily. \\
\hline Primary endpoint of the study & $\begin{array}{l}\text { Progression of } C M V \text { retinitis within four weeks of initiation of treatment determined as growth of lesion } \geq 750 \\
\mu \mathrm{m} \text { or a new retinitis lesion measuring } \geq 750 \mu \mathrm{m} \text { in diameter. }\end{array}$ \\
\hline $\begin{array}{l}\text { Secondary endpoint } \\
\text { of the study }\end{array}$ & $\begin{array}{l}\text { Secondary outcome measures included the achievement of a satisfactory response to induction treatment during } \\
\text { the first four weeks, as determined by analysis of retinal photographs. A satisfactory response was achieved when } \\
\text { all of the following criteria were met: no movement of a lesion border by I } 500 \mu \mathrm{m} \text { or more and no development } \\
\text { of a new lesion I } 500 \mu \mathrm{m} \text { or more in diameter between base line and week } 4 \text {, no movement of a lesion border by } \\
750 \mu \mathrm{m} \text { or more and no development of a new lesion } 750 \mu \mathrm{m} \text { or more in diameter between week } 2 \text { and week } 4 \text {, } \\
\text { no increase in retinitis activity between week } 2 \text { and week } 4 \text {, and a decrease in retinitis activity between base line } \\
\text { and week } 4 \text { by at least two steps on the six-step activity scale. }\end{array}$ \\
\hline Bioavailability of valganciclovir & $60 \%$, about 10 -fold higher than the oral ganciclovir. \\
\hline Outcomes of the study & $\begin{array}{l}10 \% \text { of patients in each arm showed progression of retinitis after four weeks. } 77 \% \text { of patients in the intravenous } \\
\text { ganciclovir arm and } 72 \% \text { of patients in the oral valganciclovir showed no progression. }\end{array}$ \\
\hline Adverse events & $\begin{array}{l}\text { Seven patients suffered retinal detachment during the first four weeks of the study. }{ }^{5} \text { Twenty percent of participants } \\
\text { experienced grade } 3-4 \text { adverse events by week } 4 \text {. }\end{array}$ \\
\hline
\end{tabular}

Abbreviation: bid, twice a day. 
CMV retinitis. Due to the low number of clinical events it was not possible to calculate the mean time to CMV retinitis progression. The mean treatment duration was 779 days. No significant difference in adverse reactions particularly hematological abnormalities were noted between the two treatment arms as seen in Table $3 .^{24}$

More than $30 \%$ of patients had diarrhea, nausea, and fever. ${ }^{4-6}$ More than $20 \%$ of patients experienced candidiasis, headache, dermatitis, neutropenia, anemia, insomnia, cough, vomiting and fatigue. 19\% experienced progression of CMV retinitis during the study. Patients with CMV retinitis progression needed multiple cycles of induction and maintenance therapy. Of the 113 patients who entered the study with unilateral retinitis, 10 (8.8\%) developed CMV retinitis in the previously unaffected eye. Adverse reactions are summarized in Table 3.

\section{Administration and dosage}

Valganciclovir is available as $496.3 \mathrm{mg}$ film-coated tablets of valganciclovir hydrochloride corresponding to $450 \mathrm{mg}$ of valganciclovir. It is stored between $15-30{ }^{\circ} \mathrm{C}$. Valganciclovir administration with food maximizes its bioavailability. Fatty foods significantly increase the bioavailability. The tablets are not to be broken or crushed because of its potential teratogenic and carcinogenic property in humans. Valganciclovir tablet is not a one-to-one substitute for ganciclovir capsules. As the bioavailability of oral valganciclovir is significantly higher than the ganciclovir capsules, patients turning from ganciclovir capsules to oral valganciclovir should be warned of possible over dosage if they take more than the prescribed valganciclovir. ${ }^{22}$ The treatment regimen is summarized in Table 4.

Patients on oral valganciclovir therapy must undergo complete ophthalmic evaluations periodically. This serves as the basis to judge the recovery of retinitis with treatment. Complete blood count with total and differential counts, serum creatinine levels 2-3 times a week during the induction phase,

Table 3 Adverse reactions (\%) noted in study WV $15705^{22}$

\begin{tabular}{lll}
\hline Adverse reaction & Valganciclovir & $\begin{array}{l}\text { Intravenous } \\
\text { ganciclovir }\end{array}$ \\
\hline Diarrhea & 16 & 10 \\
Nausea & 8 & 14 \\
Anemia & 8 & 8 \\
Neutropenia $($ Neutrophil & 11 & 13 \\
count $\left.<1000 / \mathrm{mm}^{3}\right)$ & & \\
Headache & 9 & 5 \\
Cathether-related & 3 & 11 \\
infections & & \\
\hline
\end{tabular}

Table 4 Treatment regimen

Induction therapy $900 \mathrm{mg}$ (two $450 \mathrm{mg}$ tablets) bid with food for 21 days. Maintenance therapy $900 \mathrm{mg}$ (two $450 \mathrm{mg}$ tablets) qd with food.

Abbreviations: qd, once a day; bid, twice a day.

and once a week during maintenance therapy is recommended to identify any hematological adverse events. ${ }^{22}$

Treatment of CMV retinitis with oral valganciclovir is suppressive but not curative. ${ }^{8}$ Valganciclovir profoundly suppresses viral replication, but does not eradicate the virus itself. Cessation of oral Valganciclovir therapy in a profoundly immunosuppressed person results in reactivation of CMV viral replication. Therefore maintenance therapy is essential in the successful management of CMV retinitis if the patient's immune function remains poor. Recent reports from the US Public Health Service (USPHS) advises discontinuation of maintenance oral valganciclovir in a patient on HAART therapy with quiescent CMV retinitis having CD4 count persistently greater than $100-150$ cells $/ \mathrm{mm}^{3}$ for at least six months, backed by cautious clinical, immunological and ophthalmological monitoring. ${ }^{25,26}$ Maintenance therapy is reconsidered if the CD4 count falls below 100-150 cells $/ \mathrm{mm}^{3}$ or the patient develops other signs of HIV progression. ${ }^{27}$

On September 12, 2003, valganciclovir was also approved for the prevention of CMV disease in kidney, ${ }^{28}$ heart, lung, ${ }^{29}$ liver, ${ }^{17}$ and pancreas transplant recipients. ${ }^{16}$ This was based on the results of the clinical trial, PV 16000, in which oral valganciclovir decreased the incidence of CMV disease, including CMV syndrome and tissue-invasive disease in the first six months after transplantation. ${ }^{22}$ Valganciclovir is currently being investigated for its efficacy in prevention and treatment of CMV end-organ disease in HIV infected patients, congenital and neonatal CMV disease and in preventing CMV disease in stem cell transplant recipients.

\section{Alternative therapies}

Approved alternative therapies for the treatment of CMV retinitis in addition to intravenous ganciclovir and oral ganciclovir include the ganciclovir intravitreal implant, intravenous foscarnet (Foscavir ${ }^{\circledR}$; AstraZeneca, Wilmington, DE, USA) and intravenous cidofovir (Vistide ${ }^{\circledR}$; Gilead, Foster City, CA, USA). ${ }^{22}$ For CMV retinitis, resistant to ganciclovir, the commonly used alternative drugs are foscarnet and cidofovir. With the exception of the study comparing oral valganciclovir to intravenous ganciclovir, there exists no head-to-head study between valganciclovir and any other drugs used in patients with CMV. Foscarnet and cidofovir act by directly inhibiting CMV DNA polymerases. They are considered second-line 
drugs in the management of CMV retinitis because of their associated adverse effects discussed in Table 5.

\section{Gancicloivir implant}

Intraocular sustained-release ganciclovir implants (Vitrasert ${ }^{\circledR}$; Chiron Vision, Irvine, CA, USA) with a release rate of $1 \mu \mathrm{g} /$ hour of ganciclovir and intravitreal injections of ganciclovir have been very effective in treating CMV retinitis. ${ }^{5,30,31}$ In the pivotal trial, patients treated with the ganciclovir implant had a mean time to CMV retinitis reactivation of 220 days compared to 70 days for patients treated with intravenous gancicloivir. ${ }^{30}$ The risk of CMV retinitis becoming bilateral was $50 \%$ at six months with the sustained-release implant alone. However biopsy confirmed the development of visceral CMV disease in $31 \%$ of patients indicating lack of protection from systemic CMV disease with the intraocular implant alone. Given that CMV retinitis is the ocular manifestation of a systemic infection, local therapy by itself must be given with awareness of systemic risks. In general, when local intraocular therapy is administered, it is done so in combination with systemic therapy typically oral valganciclovir.

\section{Intravenous foscarnet}

A direct comparison of ganciclovir and foscarnet was conducted in an open-label, randomized, multicenter clinical trial sponsored by Studies of Ocular Complications of AIDS Research Group (SOCA) in patients with AIDS and CMV. In the ganciclovir group, induction therapy with intravenous ganciclovir sodium at $5 \mathrm{mg} / \mathrm{kg}$ twice a day for two weeks was followed by maintenance therapy of $5 \mathrm{mg} / \mathrm{kg}$ per day. In the foscarnet group, induction therapy with intravenous foscarnet sodium at $90 \mathrm{mg} / \mathrm{kg}$ twice a day for two weeks was followed by maintenance therapy of $120 \mathrm{mg} / \mathrm{kg}$ per day. Retinitis progression, visual acuity, visual fields, mortality and morbidity were the outcome parameters. The mortality rate was significantly different between the two groups. Median survival times were 8.5 months for the ganciclovir group and 12.6 months for the foscarnet group. The median times to retinitis progression were similar between groups (53 days for foscarnet and 47 days for ganciclovir), and no significant difference was detected in visual acuity outcomes and visual field loss $\left(29^{\circ}\right.$ per month for foscarnet and $31^{\circ}$ per month for ganciclovir), and retinal area involvement on fundus photographs. ${ }^{32}$

\section{Intravenous cidofovir}

The SOCA sponsored HPMPC (cidofovir) Peripheral Cytomegalovirus Retinitis Trial suggested the effectiveness of both high-dose and low-dose cidofovir in controlling CMV retinitis when given as intravenous infusions intermittently. This was a multicenter, randomized, and controlled trial evaluating the role of intravenous cidofovir as a treatment for CMV retinitis. Sixty-four AIDS patients with small, peripheral, untreated CMV retinitis were enrolled for the study. These patients were assigned to one of three groups as described here: the deferral group, in which cidofovir treatment was withheld until CMV retinitis was found progressive; the low-dose cidofovir group received cidofovir, $5 \mathrm{mg} / \mathrm{kg}$ of body weight once a week for two weeks, then maintenance therapy with cidofovir, $3 \mathrm{mg} / \mathrm{kg}$ of body weight once every two weeks; or the third treatment group of high-dose cidofovir receiving $5 \mathrm{mg} / \mathrm{kg}$ of cidofovir once a week for two weeks followed by maintenance therapy of cidofovir, $5 \mathrm{mg} / \mathrm{kg}$ once every two weeks. Concomitant administration of cidofovir with probenecid, adequate hydration, intermittent dosing and monitoring for proteinuria was found to minimize associated nephrotoxicity of cidofovir. In the low-dose cidofovir group, the median time to retinitis progression was 64 days and it

Table 5 Alternative therapies for CMV disease ${ }^{15}$

\begin{tabular}{|c|c|c|c|c|}
\hline Parameter & Ganciclovir $^{9}$ & Valganciclovir ${ }^{22}$ & Cidofovir & Foscarnet $^{44}$ \\
\hline Induction therapy & IV 5 mg/kg for two weeks & $\begin{array}{l}900 \mathrm{mg} \text { bid } \\
\text { for three weeks }\end{array}$ & $\begin{array}{l}5 \mathrm{mg} / \mathrm{kg} \text { weekly } \\
\text { for two weeks }\end{array}$ & $\begin{array}{l}\text { IV } 60 \mathrm{mg} / \mathrm{kg} \text { tid } \\
\text { for two weeks }\end{array}$ \\
\hline Maintenance therapy & IV 5 mg/kg qd & $900 \mathrm{mg}$ qd & $\begin{array}{l}\text { IV } 5 \text { mg/kg every } \\
\text { two weeks }\end{array}$ & IV 30 mg/kg tid \\
\hline Advantages & $\begin{array}{l}\text { Systemic therapy, oral } \\
\text { therapy, long acting } \\
\text { implants available }\end{array}$ & $\begin{array}{l}\text { Systemic therapy, } \\
\text { oral therapy, } \\
\text { low pill burden, } \\
\text { convenient dosing }\end{array}$ & $\begin{array}{l}\text { Systemic therapy, } \\
\text { least expensive, } \\
\text { suppresses } \\
\text { exacerbations }\end{array}$ & Systemic therapy \\
\hline Adverse effects & $\begin{array}{l}\text { Myelosuppressant, large pill burden, } \\
\text { Intravenous regimen and infusion } \\
\text { related problems, if orally- poor } \\
\text { bioavailability }\end{array}$ & Myelosuppressant & $\begin{array}{l}\text { Nephrotoxic, } \\
\text { Co-administration } \\
\text { with probenicid }\end{array}$ & $\begin{array}{l}\text { Nephrotoxic, electrolyte } \\
\text { imbalance, intravenous } \\
\text { regimen and infusion- } \\
\text { related problems }\end{array}$ \\
\hline
\end{tabular}

Abbreviations: IV, intravenous; qd, once a day; bid, twice a day; tid, three times a day. 
was 21 days in the deferral group. In the high-dose group, the median time to progression was not reached at all. In conclusion, both high- and low-dose intravenous cidofovir delayed the progression of CMV retinitis effectively. ${ }^{33}$

\section{Combination therapy of intravenous ganciclovir and foscarnet}

In the SOCA-CMV Retinitis Retreatment Trial, for the relapsed retinitis, the combination of intravenous ganciclovir and foscarnet was found to be more effective than either drug alone. Combination of ganciclovir sodium at $5 \mathrm{mg} / \mathrm{kg}$ per day and foscarnet sodium at $90 \mathrm{mg} / \mathrm{kg}$ per day was the treatment regimen in the study. Combination therapy was found to be the most effective regimen in controlling retinitis progression, as evaluated by the centralized Fundus Photograph Reading Center in a masked fashion. The median times to retinitis progression were 1.3 months, 2.0 months, and 4.3 months in the foscarnet group, ganciclovir group, and combination therapy group, respectively. Quality-of-life parameters were found to be best with the combination therapy compared to the monotherapy groups of ganciclovir and foscarnet. ${ }^{33}$ However, infusion times and systemic side effects are significant, and in the HAART era, this treatment approach is rarely utilized.

\section{Combination of ganciclovir implant and oral ganciclovir with intravenous cidofovir}

In vitro data suggest that combination therapies are synergistic in inhibiting viral replication. Therefore, the combination of daily oral ganciclovir and intermittent intravenous cidofovir was thought to be an attractive therapy for relapsed disease as both these act in synergy to control the systemic and ocular CMV disease.

The Ganciclovir-Cidofovir CMV Retinitis Trial (GCCRT) was a randomized, multicenter clinical trial aimed at comparing the regimen of the ganciclovir implant plus oral ganciclovir to one of intravenous cidofovir for the treatment of CMV retinitis. Sixty-one patients with AIDS and $\mathrm{CMV}$ retinitis were randomized either to the regimen of the ganciclovir implant plus oral ganciclovir, 1 gm three times daily, or intravenous cidofovir, $5 \mathrm{mg} / \mathrm{kg}$ once a week for two weeks, followed by $5 \mathrm{mg} / \mathrm{kg}$ every other week. The results were as follows: Ocular outcomes were similar between the two groups, with retinitis progression occurring at a rate of 0.67 per person-year in the ganciclovir group, 0.71 per person-year in the cidofovir group, and a 15-letter loss of visual acuity occurring at a rate of 0.78 per person-year in the ganciclovir group and 0.47 per person-year in the cidofovir group. Vitreous hemorrhage associated with the surgical procedure of placing the implant was noted in the ganciclovir implant group ( 0.13 per person-year) with no cases in the cidofovir group. Conversely, uveitis occurred more frequently in the cidofovir group ( 0.35 per personyear) than in the ganciclovir group (0.09 per person-year). Mortality rates were not different between groups $(0.41$ per person-year for ganciclovir and 0.49 per person-year for cidofovir). Nephrotoxicity, the main systemic side effect of cidofovir was significantly more common in the cidofovir group ( 0.48 per person-year) compared to the ganciclovir group ( 0.18 per person-year). ${ }^{34}$

\section{Advantages of systemic therapy with valganciclovir}

1. Systemic treatment with oral ganciclovir reduced the incidence of systemic CMV disease. ${ }^{35}$ The effectiveness of systemic ganciclovir is emphasized by the fact that there is an increase of $22 \%-35 \%$ in the incidence of new CMV retinitis in the untreated contralateral eye with intraocular treatment alone. ${ }^{36}$

2. The convenient administration of valganciclovir has resulted in better patient compliance as suggested in a study by Claxton. ${ }^{37}$

3. In a study with oral ganciclovir, it has been found to prevent CMV disease in patients with HIV infection and CD 4 count of lesser than 100 cells $/ \mathrm{mm}^{3}$. Hence, oral valganciclovir/ganciclovir holds promise in preventing CMV disease in patients with HIV infection. ${ }^{38}$

4. Systemic treatment reduces mortality. ${ }^{13}$

\section{Resistance to valganciclovir}

Viral resistance to ganciclovir has been noted with prolonged treatment in patients with CMV retinitis and was first reported in 1989. Ganciclovir resistance has been attributed to the mutations in protein kinase gene UL97 and polymerase gene UL54. ${ }^{22}$ The incidence of ganciclovir resistance in valganciclovir therapy is similar to that in intravenous ganciclovir therapy. Patients showing poor clinical response but with persistent viral excretion are considered to have developed resistance to ganciclovir. In a study involving 72 immunocompromised patients with HIV and CMV retinitis, $20 \%$ of patients who failed to respond to valganciclovir were found to have nine different resistant strains of CMV. ${ }^{39}$ All these patients failed to phosphorylate ganciclovir. Surprisingly in some patients, valganciclovir resistance was noticed without any prior exposure to ganciclovir. In another study, genotypic 
resistance to ganciclovir was found in $9.4 \%$ of patients after 182 days of therapy. ${ }^{40}$

\section{Mutation in viral protein kinase gene UL97}

Deletion of four amino acids in a highly conserved region of viral protein kinase results in a mutation of UL97, viral protein kinase gene. These viral mutants fail to phosphorylate ganciclovir efficiently and this is the main cause for CMV resistance to ganciclovir. ${ }^{22}$

\section{Mutation in viral polymerase gene UL54}

Mutation in viral polymerase gene UL54 has resulted in cross-resistance with other antiviral drugs acting on viral DNA polymerase such as cidofovir and foscarnet. ${ }^{22}$ This leads to reduced incorporation of the drug into the CMV DNA strand.

\section{Drug interactions}

No drug-drug in vivo interaction has been studied with valganciclovir. Valganciclovir is rapidly and extensively converted to ganciclovir and hence the same drug interactions with ganciclovir are seen with valganciclovir. ${ }^{22}$ The important drug interactions are discussed in Table 6.

\section{Adverse effects}

\section{General}

The common adverse events reported during maintenance therapy are diarrhea, nausea, vomiting, abdominal pain, fever, headache, insomnia, tremors, peripheral neuropathy, seizures, confusion, paresthesia, hallucinations, graft rejection, constipation, back pain, high blood pressure and retinal detachment. $^{22,23}$

\section{Myelosuppressant}

Less than $5 \%$ patients had serious adverse reactions such as pancytopenia and aplastic anemia. ${ }^{22,41}$

\section{Teratogenic}

Valganciclovir is a FDA pregnancy category-C drug with reproductive toxicity similar to ganciclovir. Common teratogenic abnormalities reported in animal models include cleft palate, hydrocephaly, microphthalmos and brachygnathia. Adequate contraception is advised to women of reproductive potential on valganciclovir. ${ }^{22}$

\section{Carcinogenic}

Although there is no human study to prove the carcinogenesis of valganciclovir, patients are warned to consider it a potential carcinogenic.

\section{Anti-fertility}

It causes azoospermia in animals due to direct cessation of spermatogenesis, without affecting testicular endocrine functioning. Suppressed fertility is reported in females in a different animal study. ${ }^{22}$

\section{Special precautions}

\section{Pediatric and geriatric population}

The effects of valganciclovir on pediatric and geriatric population have not been studied. Caution is to be exercised while using valganciclovir in the elderly keeping in mind the increased frequency of impaired renal, hepatic and cardiac function in them.

\section{Nursing mothers}

It is not known whether ganciclovir is secreted in human milk. Nursing mothers are instructed not to breast-feed if

Table 6 Valganciclovir drug interactions ${ }^{22}$

\begin{tabular}{|c|c|c|}
\hline Valganciclovir interactions with & Drug interactions & Comments \\
\hline Zidovudine & Myelosuppression & $\begin{array}{l}\text { This calls for reduction in valganciclovir dosage } \\
\text { or substitution with a different antiretroviral drug. }\end{array}$ \\
\hline Didanosine & $\begin{array}{l}\text { Paradoxical decline in the CD4 } \\
\text { cell counts, despite persistent } \\
\text { suppression of viral load }\end{array}$ & $\begin{array}{l}\text { The probable explanation is the inhibition of } \\
\text { purine nucleoside phosphorylase by ganciclovir } \\
\text { and its prodrug valganciclovir. }\end{array}$ \\
\hline Mycophenolate mofetil ${ }^{22}$ & Myelosuppression & $\begin{array}{l}\text { Granulocytopenia reversed with } \\
\text { granulocyte-colony stimulating factor }\end{array}$ \\
\hline Probenecid ${ }^{22}$ & $\begin{array}{l}\text { Reduces renal clearance and } \\
\text { increases plasma concentration }\end{array}$ & Close monitoring advised \\
\hline Imipenem/cilastatin & Induces convulsions & No human studies done \\
\hline Stavudine/zalcitabine/trimethoprim ${ }^{22}$ & No untoward effects reported & \\
\hline $\begin{array}{l}\text { Nephrotoxic drugs such as aminoglycosides, } \\
\text { cisplatin, tacrolimus and amphotericin } \mathrm{B}^{12}\end{array}$ & Increased nephrotoxicity & Avoidance or cautious administration is advised \\
\hline
\end{tabular}


they are on valganciclovir. The Centers for Disease Control also recommend HIV-infected mothers not to breast feed their infants to avoid postnatal transmission of HIV.

\section{Contraindications}

Valganciclovir is contraindicated in patients with ganciclovir hypersensitivity. It is contraindicated in patients with absolute neutrophil count less than $500 / \mathrm{mm}^{3}$, platelet count less than $25,000 / \mathrm{mm}^{3}$ or the hemoglobin less than $8 \mathrm{~g} / \mathrm{dL} .^{22,42}$

Valganciclovir is not advised in patients on hemodialysis or in those with creatinine clearance below $10 \mathrm{ml} /$ minute, as the optimal daily dosage is less than $450 \mathrm{mg}$. There is no study regarding the effects of peritoneal dialysis on the excretion of valganciclovir. ${ }^{14}$

\section{Drug economics}

Oral valganciclovir is an efficient and advantageous substitute for ganciclovir in many ways. It is an effective alternative to intravenous ganciclovir ${ }^{43}$ in induction and maintenance therapy of CMV retinitis in HIV patients, and is found to achieve significantly higher systemic levels than oral ganciclovir. Based on the wholesale prices in the United States, a two-week induction therapy with intravenous ganciclovir costs US\$1,583, while oral valganciclovir costs US\$2,136. For maintenance treatment, intravenous ganciclovir costs US\$57 each day, and oral valganciclovir costs US\$76 each day.

Valganciclovir is cost and time effective as it eliminates the expenses involved in hospitalization, intravenous, or indwelling catheterizations and nursing care associated with the use of parenteral ganciclovir, foscarnet or cidofovir. ${ }^{15,38,44}$ Long-term intravenous therapy predisposes the patient to the risk of catheter-related complications such as thrombophlebitis, intravenous line infection and sepsis. ${ }^{45}$ Although valganciclovir is more expensive per pill than ganciclovir, the costs are comparable with intravenous ganciclovir taking into account the cost of parenteral administration. ${ }^{42}$ Valganciclovir has overcome the large pill burden of oral ganciclovir and has improved treatment adherence. Roche has agreed to offer valganciclovir at a price of US\$1800 for two weeks in developing countries of Africa and Asia, after negotiations with Médecins Sans Frontières's (MSF) Access to Essential Medicines Campaign. ${ }^{11}$

\section{Conclusions}

Valganciclovir is a relatively safe, highly bioavailable oral form of ganciclovir that has greatly enhanced the efficacy of preventive and maintenance treatment regimens for CMV retinitis in AIDS patients. Valganciclovir is the only drug with bioavailability equivalent to the intravenous ganciclovir and is indicated for the treatment of serious vision and life-threatening CMV infections. ${ }^{5}$ Valganciclovir in AIDS patients has been shown to be highly effective for the induction and maintenance of CMV disease, and has significantly improved quality of life for patients with this disease as it has eliminated the need for chronic indwelling catheterization and chronic intravenous therapy for people with CMV retinitis.

\section{Disclosures}

The authors report no conflicts of interest in this work.

\section{References}

1. Gallant JE, Moore RD, Richman DD, Keruly J, Ghaisson RE, et al. Incidence and natural history of cytomegalovirus disease in patients with advanced human immunodeficiency virus disease treated with zidovudine. The Zidovudine Epidemiology Study Group. J Infect Dis. 1992;1666:1223-1227.

2. Kuppermann BD, Petty JG, Richman DD, et al. Correlation between $\mathrm{CD} 4+$ counts and prevalence of cytomegalovirus retinitis and human immunodeficiency virus-related noninfectious retinal vasculopathy in patients with acquired immunodeficiency syndrome. Am J Ophthalmol. 1993; 1155:575-582.

3. Whitley RJ, Jacobson MA, Friedberg DN, et al. Guidelines for the treatment of cytomegalovirus diseases in patients with AIDS in the era of potent antiretroviral therapy: recommendations of an international panel. International AIDS Society-USA. Arch Intern Med. 1998;1589: 957-969.

4. Jung D, Dorr A. Single-dose pharmacokinetics of valganciclovir in HIVand CMV-seropositive subjects. J Clin Pharmacol. 1999;398:800-804.

5. Martin DF, Sierra-Madero J, Walmsley S, et al. A controlled trial of valganciclovir as induction therapy for cytomegalovirus retinitis. $N E n g l$ J Med. 2002;34615:1119-1126.

6. Brown F, Banken L, Saywell K, Arum I. Pharmacokinetics of valganciclovir and ganciclovir following multiple oral dosages of valganciclovir in HIV- and CMV-seropositive volunteers. Clin Pharmacokinet. 1999;372:167-176.

7. Karmel M. Get Drugs Straight to the Eye. Eye Net. 2006. Cited 2006 Jan. Available from: http://www.aao.org/publications/eyenet/200601/ feature.cfm. Accessed Nov 20, 2009.

8. Marco M. Valganciclovir: a new treatment for cytomegalovirus retinitis. San Francisco AIDS Foundation Beta. 2002;151:19-21.

9. Skiest DJ. Cytomegalovirus retinitis in the era of highly active antiretroviral therapy (HAART). Am J Med Sci. 1999;3175:318-335.

10. Bowen EF, Wilson P, Atkins M, et al. Natural history of untreated cytomegalovirus retinitis. Lancet. 1995;346:1671-1673.

11. Heiden D, Ford N, Wilson D, et al. Cytomegalovirus retinitis: the neglected disease of the AIDS pandemic. PLoS Med. 2007;412:e334.

12. Segarra-Newnham M, Salazar MI. Valganciclovir: A new oral alternative for cytomegalovirus retinitis in human immunodeficiency virusseropositive individuals. Pharmacotherapy. 2002;229:1124-1128.

13. Kempen JH, Jabs DA, WIlson LA, Dunn JP, West SK, Tonascia J. Mortality risk for patients with cytomegalovirus retinitis and acquired immune deficiency syndrome. Clin Infect Dis. 2003;3710:1365-1373.

14. Czock D, Scholle C, Rasche FM, Schaarschmidt D, Keller F. Pharmacokinetics of valganciclovir and ganciclovir in renal impairment. Clin Pharmacol Ther. 2002;72:142-150. 
15. Cvetkovic RS, Wellington K. Valganciclovir: a review of its use in the management of CMV infection and disease in immunocompromised patients. Drugs. 2005;656:859-878.

16. AIDSInfo.nih.gov. 2007. Updated 2007 Mar 16. Rockville, MD: US Department of Health and Human Services Online. Available from: http://www.aidsinfo.nih.gov/DrugsNew/DrugDetailNT.aspx?MenuIt em=Drugs\&Search=On\&int_id = 271. Accessed on Nov 20, 2009.

17. Pescovitz MD, Rabkin J, Merion RM, et al. Valganciclovir results in improved oral absorption of ganciclovir in liver transplant recipients. Antimicrob Agents Chemother. 2000;4410:2811-2815.

18. Ganapathy ME, Huang W, Wang H, et al. Valacyclovir: a substrate for the intestinal and renal peptide transporters PEPT1 and PEPT2. Biochem Biophys Res Commun. 1998;2462:470-475.

19. Sinko PJ, Balimane PV, Balimane. Carrier-mediated intestinal absorption of valacyclovir, the L-valyl ester prodrug of acyclovir: 1. Interactions with peptides, organic anions and organic cations in rats. Biopharm Drug Dispos. 1998;194:209-217.

20. Griffy KG. Pharmacokinetics of oral ganciclovir capsules in HIV-infected persons. AIDS. 1996;10(Suppl 4):3-6.

21. Sagedal S, Nordal KP, Hartmann A, et al. Pre-emptive therapy of CMVpp65 antigen positive renal transplant recipients with oral ganciclovir: a randomized, comparative study. Nephrol Dial Transplant. 2003;189:1899-1908

22. Drugs.com. Auckland. Drugsite Trust online. 2009. Updated on 2009 Oct 26. Available from: http://www.drugs.com/pro/valcyte.html. Accessed on Nov 20, 2009.

23. Curran M, Noble S. Valganciclovir. Drugs. 2001;618:1145-1150.

24. Lalezari J, Lindley J, Walmsley S, et al. Intravenous cidofovir for peripheral cytomegalovirus retinitis in patients with AIDS. A randomized, controlled trial. Ann Intern Med. 1997;1264:257-263.

25. Deayton JR, Griffiths PD. When can cytomegalovirus prophylaxis and maintenance therapy be stopped in HIV disease? Curr Opin Infect Dis. 2000;136:637-641.

26. Sklar PA, Agyemang AF, Monastra R, et al. Five-year follow-up of a cohort of profoundly immunosuppressed patients discontinuing therapy for cytomegalovirus retinitis. AIDS. 2004;183:567-569.

27. 2004 USPHS/IDSA Guidelines for the Treatment of Opportunistic Infections in Adults and Adolescents Infected with Human Immunodeficiency Virus: U.S. Public Health Service (USPHS) and Infectious Diseases Society of America (IDSA). MMWR Recomm Rep. 2004;53:53 (RR-15):1.

28. Babel N, Gabdrakhmanova L, Juergensen JS, et al. Treatment of cytomegalovirus disease with valganciclovir in renal transplant recipients: a single center experience. Transplantation. 2004;782:283-285.

29. Fellay J, Venetz JP, Aubert JD, Seydoux C, Pascual M, Meylan PR. Treatment of cytomegalovirus infection or disease in solid organ transplant recipients with valganciclovir. Transplant Proc. 2005;372:949-951.

30. Musch DC, Martin DF, Gordon JF, et al. Treatment of cytomegalovirus retinitis with a sustained-release ganciclovir implant. The Ganciclovir Implant Study Group. N Engl J Med. 1997;3372:83-90.

31. Martin DF, Kuppermann BD, Wolitz RA, Palestine AG, Li H, Robinson CA, et al. Oral ganciclovir for patients with cytomegalovirus retinitis treated with a ganciclovir implant. Roche Ganciclovir Study Group. NEngl J Med. 1999;34014:1063-1070.

Clinical Ophthalmology

\section{Publish your work in this journal}

Clinical Ophthalmology is an international, peer-reviewed journal covering all subspecialties within ophthalmology. Key topics include: Optometry; Visual science; Pharmacology and drug therapy in eye diseases; Basic Sciences; Primary and Secondary eye care; Patient Safety and Quality of Care Improvements. This journal is indexed on
32. Studies of the Ocular Complications of AIDS Research Group, AIDS Clinical Trials Group. Foscarnet-Ganciclovir Cytomegalovirus Retinitis Trial. 4. Visual outcomes. Ophthalmology. 1994;1017:1250-1261.

33. Studies of the Ocular Complications of AIDS Research Group, AIDS Clinical Trials Group. Combination foscarnet and ganciclovir therapy vs monotherapy for the treatment of relapsed cytomegalovirus retinitis in patients with AIDS. The Cytomegalovirus Retreatment Trial. Arch Ophthalmol. 1996;1141:23-33.

34. Studies of the Ocular Complications of AIDS Research Group, AIDS Clinical Trials Group. Parenteral cidofovir for cytomegalovirus retinitis in patients with AIDS: the HPMPC peripheral cytomegalovirus retinitis trial. A randomized, controlled trial. Ann Intern Med. 1997;1264: 264-274.

35. Morinelli EN, Dugel PU, Lee M, Klatt EC, Rao NA, et al. Opportunistic intraocular infections in AIDS. Trans Am Ophthalmol Soc. 1992;90: 97-108; discussion 108-109.

36. Ausayakhun S, Watananikorn S, Ngamtiphakorn S, Prasitsilp J. Intravitreal foscarnet for cytomegalovirus retinitis in patients with AIDS. $J$ Med Assoc Thai. 2005;881:103-107.

37. Claxton AJ, Cramer J, Pierce C, et al. A systematic review of the associations between dose regimens and medication compliance. Clin Ther. 2001;238:1296-1310.

38. Oppenheimer F, Gonzalex-Molina M, Rubio M. Cost of prophylaxis in the management of cytomegalovirus infection in solid organ transplant recipients. Clin Transplant. 2007;214:441-448.

39. Stanat SC, Reardon JE, Erice A, Jordan MC, Drew WL, Biron KK. Ganciclovir-resistant cytomegalovirus clinical isolates: mode of resistance to ganciclovir. Antimicrob Agents Chemother. 1991;35: 2191-2197.

40. Boivin G, Goyette N, Gilbert C, Covington E. Analysis of cytomegalovirus DNA polymerase (UL54) mutations in solid organ transplant patients receiving valganciclovir or ganciclovir prophylaxis. $\mathrm{J} \mathrm{Med}$ Virol. 2005;773:425-429.

41. Walmsley S, Tseng A. Comparative tolerability of therapies for cytomegalovirus retinitis. Drug Saf. 1999;213:203-224.

42. Infectious-diseases.jwatch.org. Waltham, MA: Journal Watch Online; 2001. Updated 2001 July 27. Available from: http://infectious-diseases. jwatch.org/cgi/content/full/2001/727/1. Accessed on Nov 20, 2009.

43. Wiltshire H, Hirankarn S, Farrell C, et al; Valganciclovir Solid Organ Transplant Study Group. Pharmacokinetic profile of ganciclovir after its oral administration and from its prodrug, valganciclovir, in solid organ transplant recipients. Clin Pharmacokinet. 2005;445: 495-507.

44. Lee CH, Bright DC, Ferrucci S, et al. Economic evaluation of systemic treatments for cytomegalovirus retinitis in patients with AIDS. Pharmacoeconomics. 2001;195(Pt 2):535-550.

45. Stanley HD, Charlebois E, Harb G, Jacobson MA. Central venous catheter infections in AIDS patients receiving treatment for cytomegalovirus disease. J Acquir Immune Defic Syndr. 1994;73: 272-278.

PubMed Central and CAS, and is the official journal of The Society of Clinical Ophthalmology (SCO). The manuscript management system is completely online and includes a very quick and fair peer-review system, which is all easy to use. Visit http://www.dovepress.com testimonials.php to read real quotes from published authors.

\section{Dovepress}

